\title{
RELATOS DE TRABALHADORES: PERCEPÇÕES DE ASPECTOS FÍSICOS E SOCIAIS DO AMBIENTE ORGANIZACIONAL
}

Taís Manso

Psicóloga formada pela Faculdade Jaguariúna.

Aline Cristina Barbosa Pires Psicóloga formada pela Faculdade Jaguariúna.

Fernando Ugo

Psicólogo formado pela Faculdade Jaguariúna.

Marilda Aparecida Dantas

Psicóloga e docente do curso de Psicologia da Faculdade Jaguariúna. Doutoranda em Educação -

Universidade Estadual de Campinas.

\begin{abstract}
Resumo
O mundo do trabalho é uma esfera da vida em que a maioria dos indivíduos, em algum momento da vida, irá vivenciar. Assim, torna-se fundamental conhecer e explorar as concepções dos trabalhadores a cerca de suas experiências e aspectos relacionados ao bem-estar e saúde. O objetivo deste trabalho foi de identificar e analisar as percepções dos trabalhadores quanto a aspectos físicos e sociais do ambiente de trabalho. Foram participantes da pesquisa 12 trabalhadores de organizações de diferentes segmentos que adoeceram no posto de trabalho e foram afastados ou necessitaram de auxílio psicológico. Após a aprovação do projeto de pesquisa pelo Comitê de Ética em Pesquisa foi realizada a coleta de dados por meio de um roteiro de entrevista semi-estruturada sobre aspectos pessoais, profissionais, sociais e percepções do trabalhador acerca do que o trabalho representa em sua vida. As respostas obtidas foram analisadas qualitativa e quantitativamente. Os relatos dos participantes indicaram a necessidade de alívio em relação ao trabalho quanto a aspectos de ritmo de trabalho e divisão de tarefas com menor carga. Outros aspectos que incomodam os trabalhadores referem-se às relações sociais, principalmente queixas da postura da liderança, na qual se sentem de certa forma desvalorizados. A presente pesquisa contribui para a ampliação do conhecimento sobre tema e para fomentar a necessidade de mais investimentos na área, a fim de possibilitar maior bem-estar aos trabalhadores de modo geral, principalmente aos aspectos biopsicossociais.
\end{abstract}

Palavras-chaves: saúde, trabalho, psicólogo. 


\title{
REPORTS OF WORKERS: PERCEPTIONS OF PHYSICAL AND SOCIAL ASPECTS OF THE ORGANIZATIONAL ENVIRONMENT
}

\begin{abstract}
The working world is a sphere of life that most people at some point in life you willexperience. Thus, it becomes essential to know and explore the views of workersabout their experiences and issues related to welfare and health. This study objective of this study is to identify and analyze the perceptions of workers about the physicaland social environment. Research participants were 12 subjects who became ill on the job and have been removed or needed psychological help from organizations of different segments. After approval of the research project by the Ethics Research was conducted to collect data through a script of semi-structured interview about personal, professional, social worker and perceptions about what the work represents in your life. The responses were analyzed qualitatively and quantitatively. The accounts of the participants indicated the need for relief in relation to work on aspects of work flow and division of tasks with lower load. Other things that annoy workers refer to social relations, especially complaints of leadership posture in which they feel somewhat devalued. This research contributes to the expansion of knowledge about the subject and the need to encourage more investment in the area, to enable greater well-being of workers in general, particularly the bio psychosocial aspects.
\end{abstract}

Keywords: health, work, psychologist.

\section{INFORMES DE LOS TRABAJADORES: LA PERCEPCIÓN DE LOS ASPECTOS FÍSICOS Y SOCIALES DEL ENTORNO DE LA ORGANIZACIÓN}

\begin{abstract}
Resumen
El mundo del trabajo es una esfera de la vida que la mayoría delas personas en algún momento de la vida que usted experimentará. Por lo tanto, se hace mi prescindible para conocer y explorar las opiniones de los trabajadores acerca de sus experiencias y las cuestiones relacionadas con el bienestar y la salud. Este objetivo del estudio de este estudio es identificar y analizar las percepciones de los trabajadores sobre el medio ambiente físico y social. Participantes en la investigación fueron 12 pacientes que se enfermaron en el trabajo y se han eliminado o necesita ayuda psicológica de las organizaciones de los diferentes segmentos. Después de la aprobación del proyecto de investigación por la Ética de la Investigación se llevó a cabo para recopilar datos a través de un guión de entrevista semi-estructurada de personal, los trabajadores profesionales, sociales y percepciones acerca de lo que la obra representa en su vida. Las respuestas se analizaron cualitativa y cuantitativamente. Las cuentas de los participantes indicaron la necesidad de ayuda en relación con el trabajo sobre los aspectos del flujo de trabajo y la división de tareas con menor carga. Otras cosas que molestan los trabajadores se refieren a las relaciones sociales, sobre todo las quejas de la postura de liderazgo en el que se sienten un tanto devaluado. Esta investigación contribuye a la expansión del conocimiento sobre el tema y la necesidad de fomentar una mayor inversión en la zona, para permitir un mayor bienestar de los trabajadores en general, en particular los aspectos biopsicosociales.
\end{abstract}

Palabras claves: salud, trabajo, psicólogo.

\section{INTRODUÇÃO}

Para iniciar uma reflexão contemporânea a acerca do trabalho, é necessário ampliar a visão de análise sobre o trabalhador. Assim, Dejours (1992) afirma que os indivíduos inseridos nas organizações de trabalho possuem uma história 
individual, são portadores de projetos, de esperanças e de desejos, mas que nem sempre estão alinhados com o cotidiano nas organizações. Para combater a angústia do trabalho e a insatisfação, os indivíduos acabam por elaborar estratégias defensivas, não sendo o sofrimento imediatamente identificável, muitas vezes disfarçado ou mascarado, podendo ser revelado de certa maneira por uma sintomatologia. Assim, o sofrimento do trabalhador acaba dando lugar a uma semiologia que é chamada de "ideologia defensiva da profissão" (p.32).

Diversas manifestações neste campo são identificáveis, ainda de acordo com o autor outra concepção importante quanto aos indivíduos nas organizações está relacionada à alienação. Esta pode ser definida como uma forma de conflito, no qual o desejo do trabalhador se capitula frente à injunção patronal, sendo então o prazer sujeito as resistências individuais atreladas a resistências coletivas, tendo como epicentro as ideologias coletivas em relação à profissão (Dejours, 1992).

Em busca de possíveis amenizações frente a esta demanda, Oliveira, Viganó, Lunardelli, Canêo e Goulart Junior (2010) afirmam que o psicólogo inserido em organizações de trabalho tem como objetivo zelar pela saúde do trabalhador, o que se dá não somente com ações remediadoras, mas, sobretudo por meio de práticas que previnam a instalação e aparecimento de transtornos mentais. Oliveira et al , 2010 apontam que muitas são as complicações que podem advir da relação do trabalhador com sua ocupação, como depressão, transtornos afetivos, alteração do ciclo vigília-sono, neurastenia, burnout e outras. Alguns fatores como excesso de trabalho, pressão por produção, turnos alternados, riscos físicos e falta de autonomia são apontados como prováveis desencadeadores da fadiga, e as consequências encontradas vão desde baixo rendimento e maior risco de acidentes de trabalho até dificuldade para relaxar em momentos de lazer.

Compartilhando desta idéia Ulhôa et al (2010) comenta que as interações compreendidas entre trabalhadores e as condições de trabalho podem afetar sua saúde. Tais interações abrangem a autonomia do trabalhador em relação à tarefa, o grau de satisfação para realização das atividades laborais, perspectivas e segurança no trabalho, bem como as relações humanas estabelecidas. Adicionalmente, as condições de trabalho que envolvem alta demanda, baixo controle e falta de apoio social podem surtir efeitos danosos à saúde física e mental de trabalhadores, como doenças cardiovasculares, distúrbios metabólicos 
e distúrbios posíquicos (depressão, ansiedade, fadiga, irritabilidade, insônia e déficit de memória e de concentração).

Segundo Souza, Carvalho, Araújo, e Portode (2010), o trabalho é um determinante do processo saúde e doença, onde o impacto sobre a saúde resulta da complexidade da relação do homem com seu trabalho, que, em decorrência das novas formas de organização e de gestão, cria situações de grande exigência para os trabalhadores. Os fatores psicossociais do trabalho envolvem aspectos como sobrecarga (excesso de tarefas, pressão de tempo e repetitividade); subcarga (monotonia, baixa demanda, falta de criatividade); falta de controle sobre o trabalho (baixo poder de decisão sobre o que e como irá fazer); distanciamento entre grupos de mandos e de subordinados; isolamento social no ambiente de trabalho; conflitos de papéis, conflitos interpessoais e falta de apoio social.

De acordo com Souza et al (2010), a teoria do modelo demanda-controle, focada na organização psicossocial do trabalho, postula que o estresse psicológico e o consequente adoecimento físico ou mental são resultados da interação entre duas características específicas do trabalho: demanda psicológica e controle. Há um aspecto importante que dificulta encontrar elementos que sirvam de base para estabelecer a relação entre trabalho e sofrimento psíquico nas organizações, não é muito comum o diagnóstico de casos graves ou claramente delineados como doença mental ou transtorno mental. Isto porque, se o sofrimento ocorre, antes de ele tornar-se um problema para a organização, o trabalhador tende de algum modo, a se afastar de sua atividade, ou dela é afastado, com diagnósticos que geralmente não refletem o que de fato sofre. Um exemplo disso, como apontado por Borsoi (2007) são os chamados "desembarques brancos" realizados por petroleiros que trabalham em plataformas marítimas. Quando não suportam mais o trabalho confinado, e antes que percam o equilíbrio necessário para se manter embarcados, buscam justificativas para desembarcar, continuando a trabalhar como petroleiros em terra.

Segundo Silva e Menezes (2008), a síndrome do esgotamento profissional (burnout) e os transtornos mentais comuns, frequentemente estão associados à incapacidade e a alto custo social, econômico e individual, absenteísmo, queda da produtividade, alta rotatividade de profissionais, alta demanda dos serviços de saúde, uso abusivo de tranquilizantes, álcool e outras drogas. Os fatores 
associados ao esgotamento profissional na literatura incluem idade, estado civil, tempo de trabalho, sobrecarga de trabalho, conflitos interpessoais e entre os ocupantes do cargo e sua clientela, falta de suporte social, de autonomia e de participação nas decisões.

De acordo com Rebouças, Legay e Abelha (2007), o campo da saúde ocupacional vêm oferecendo contribuições importantes para o entendimento das repercussões do trabalho sobre a saúde e o bem-estar de profissionais. O conhecimento na área permite confirmar que a saúde mental dos trabalhadores está relacionada com aspectos do trabalho. Portanto, o estabelecimento dessa relação é tarefa de grande complexidade, não apenas pelas próprias características dos distúrbios psíquicos, mas pelas dificuldades inerentes à investigação de associações entre fenômenos subjetivos. Um estudo feito por Sato e Bernardo (2005) foi possível observar que os trabalhadores se sentiam mais autorizados a procurar ajuda por problemas de ordem física, sendo rara a procura quando em quadro inicial de questões de ordem mental. Os pesquisadores também destacam que expressões como ritmo alucinante, trabalho incessante, loucura e desespero são utilizados com frequência como forma de expor o sofrimento enfrentado em detrimento das características das organizações.

Outra pesquisa realizada com trabalhadores é a de Ulhôa et al (2010), que investigou os motoristas de caminhão, que frequentemente estão sujeitos a longas jornadas de trabalho, e a horários irregulares devido à urgência nas entregas de mercadorias. A necessidade de dirigir por muitas horas compromete o sono, causa sonolência no trabalho e aumenta o risco de acidentes. Esses trabalhadores se expõem aos estressores de ordem ambiental, como as condições das estradas e tráfego intenso, e aos estressores de natureza organizacional, como o tipo de turno e o vínculo de trabalho. Ulhôa et al (2010) comenta ainda que tais condições de trabalho levam à adoção de estilos de vida inadequados, com o consumo de álcool e fumo, além do sedentarismo.

Nascimento, Nascimento e Silva (2007) complementam quanto ao consumo de álcool e anfetaminas entre caminhoneiros, que vem aumentando nos últimos anos e se tornando um sério problema de saúde pública. Os caminhoneiros de estrada representam uma categoria profissional de grande importância na economia do Brasil. Entretanto, encontrar alternativas para minimizar o consumo abusivo dessas substâncias e conscientizar sobre seus 
riscos constitui um grande desafio, assim como melhorar suas condições de trabalho e qualidade de vida.

Outros profissionais foram estudados por Santos e Cardoso (2010) que evidenciaram a vulnerabilidade ao stress em trabalhadores de saúde mental que estão expostos a elevada demanda emocional. Os participantes da pesquisa responderam ao Inventário de Sintomas de Stress para Adultos de Lipp e um roteiro complementar. O estudo demonstrou que 36\% apresentaram manifestação de stress, $44 \%$ avaliaram-se como muito estressados e $60 \%$ apresentaram alto esgotamento emocional, sendo que os indicadores de stress apresentados pelos participantes são predominantemente de natureza física, manifestados por meio de sintomas como tensão muscular, taquicardia, dores de cabeça, desgaste físico constante, entre outros. Estes sintomas podem interferir de modo negativo na disposição do indivíduo, inclusive em suas atividades laborais que estão voltadas ao cuidado do usuário. O estudo também demonstrou que existe uma ligação entre idade e experiência no campo profissional, o que sugere que profissionais mais novos apresentam um maior sentimento de sobrecarga pelo trabalho e uma atitude de distanciamento direcionada aos colegas e ao trabalho, trabalho de Fontes, Neri e Yassuda (2010) também fez essa identificação.

Verificando a relevância destes achados Santos e Cardoso (2010) apontam a necessidade da criação de espaços voltados para construção de um novo tipo de trabalho que procure valorizar a saúde do trabalhador, a cidadania, o respeito ao outro e a alteridade. Também apontam a necessidade de se instituir programas voltados para saúde do trabalhador, tendo em vista o desenvolvimento de recursos para lidar com o stress e com as dificuldades inerentes aos trabalhos realizados pro profissionais em saúde mental.

Outros profissionais da saúde, como os enfermeiros, foram investigados por Manetti e Marziale (2007). Os autores investigaram fatores associados à depressão e a relação com o absenteísmo no trabalho. Especificamente, dentre os trabalhadores de enfermagem a literatura investigada pelas pesquisadoras colaborou de forma a demonstrar que os fatores associados à depressão e desencadeadores dela podem estar relacionados a fatores internos ao ambiente e processo de trabalho, como: os setores de atuação profissional, o turno, o relacionamento interpessoal, a sobrecarga, serviço, os problemas na escala, a autonomia na execução de tarefas, a assistência a clientes, o desgaste, o suporte 
social, a insegurança, o conflito de interesses e as estratégias de enfrentamento desenvolvidas. Assim também fatores externos ao trabalho, como: sexo, idade, carga de trabalho doméstico, suporte e renda familiar, estado de saúde geral do trabalhador, e as características individuais.

Portanto dentre esses diversos apontamentos, o objetivo deste trabalho é de identificar e analisar as percepções dos trabalhadores quanto a aspectos físicos e sociais do ambiente de trabalho. Os dados são discutidos à luz das implicações no contexto do trabalho.

\section{MÉTODO}

A presente pesquisa caracteriza-se pelo delineamento de levantamento descritivo. A seguir apresenta-se a metodologia utilizada:

\section{Participantes}

Foram participantes da pesquisa 12 sujeitos que adoeceram no posto de trabalho e foram afastados ou necessitaram de auxílio psicológico. A idade variou entre 27 a 59 anos, de ambos o sexo. O nível de escolaridade de maior predominância foi o de ensino médio (7), seguido de ensino fundamental (3), ensino técnico (1) e nível superior (1). O estado civil dos sujeitos era: casados (2), amasiados (2), separados (5) e divorciados (3).

Dentre os motivos dos afastamentos, foram encontradas as seguintes razões: depressão e/ou síndrome do pânico (3), artrose e/ou tendinite (4), problemas de coluna e/ou braços (4), e acidente de trabalho (2). O período do afastamento variou de 11 meses à 11 anos (quatro sujeitos afastaram-se apenas uma vez, quatro sujeitos afastaram-se por 2 vezes e quatro sujeitos afastaramse mais de duas vezes).

O tempo que esses trabalhadores exercem suas funções em suas respectivas empresas variou entre um ano e mais de quinze anos de trabalho, atuantes nos seguintes ramos: serviço público (4), alimentício (1), metalúrgico (4), marmoraria (1), costura (1) e zeladoria (1). Em relação ao porte da empresa foram: pequeno (3), médio (3) e grande (6). Quanto ao número de horas trabalhadas $75 \%$ dos sujeitos entrevistados trabalham em horário administrativo (8 horas por dia). 


\section{Material}

Para a coleta de dados foi utilizado um roteiro de entrevista semiestruturada, com critério de avaliação qualitativo e quantitativo. O roteiro de entrevista continha 17 questões abertas, elaborado pelos pesquisadores baseado nos objetivos da presente investigação, tendo como referência Luz (2007). O roteiro da entrevista englobou aspectos pessoais, profissionais, sociais e percepções dos trabalhadores acerca do que o trabalho representa em sua vida.

\section{Procedimento}

A pesquisa foi aprovada pelo Comitê de Ética em Pesquisa da Faculdade de Ciências Médicas da UNICAMP sob parecer 615/2011. Os participantes foram convidados a participar voluntariamente da pesquisa por meio da estratégia descrita a seguir.

Os pesquisadores obtiveram o apoio do CEREST (Centro de Referência de Saúde do Trabalhador) regional do interior de São Paulo. O apoio foi em relação ao agendamento das entrevistas, conforme disponibilidade dos envolvidos, que aconteceram no próprio centro, numa sala reservado para a pesquisa, mantendo os critérios de sigilo e ética, dispostos no Termo de Consentimento Livre e Esclarecido (TCLE). A entrevista foi individual e gravada para posterior transcrição dos dados com tempo aproximado de 30 minutos.

\section{RESULTADOS E DISCUSSÃO}

As análises dos relatos foram realizadas de duas formas: a qualitativa e a quantitativa. Na análise qualitativa, os pesquisadores identificaram aspectos relevantes (queixas e críticas) nos relatos dos participantes, de modo que em função das perguntas realizadas são apresentadas as falas que as ilustram. Na análise quantitativa, a partir das respostas foram identificadas aquelas com maior frequência na qual são descritas por porcentagem. Os relatos dos participantes são apresentados sem a identificação deles a fim de preservar o sigilo.

Os relatos foram transcritos e agrupados de acordo com as temáticas de análise: Ambiente físico e ritmo de trabalho, como: equipamentos e layout; Relações sociais dos trabalhadores; Satisfação e Motivação; 
Ambiente físico e ritmo de trabalho, como: Equipamentos e layout

A maioria dos trabalhadores (62\%) reconhece a necessidade de melhoria no ambiente de trabalho, apontando como precária as condições e com baixa melhoria no decorrer do tempo. São relatados aspectos físicos quanto à temperatura, ventilação, pintura, automatização e organização do espaço, de modo que sentem o impacto desses fatores em suas moléstias. Quanto a equipamento de segurança, reconhecem algum avanço do uso com o passar do tempo, mas notam que em alguns casos ocorre algum tipo de omissão quanto à disponibilidade do recurso. "Agente trabalha em temperatura ambiente, há muita falta de disciplina, de coordenação no setor. O desgaste do dia, mais o emocional pesa muito pra quem passa pelos seus 30, 40 anos." (Sujeito 10)

Reconhecem ainda o impacto do trabalho operacional em suas condições psicológicas. "Eu sou uma pessoa acelerada, se eu me proponho, com dor ou sem dor eu faço, por isso eu travo tanto, porque eu não consigo relaxar. Eu preciso resolver as coisas, por ter agilidade e por ser elogiada, cada vez mais eu me cobro, entro em depressão, porque eu sinto que fracassei." (Sujeito 5).

Quando se trata de ambiente físico e ritmo de trabalho, os trabalhadores ficaram bem divididos em suas respostas na avaliação de ambiente de trabalho em relação às condições físicas, equipamentos de segurança, máquinas e divisão do trabalho, se consideram justa a divisão das tarefas atribuídas a eles de acordo com o tempo estipulado para desempenhar suas tarefas, $33 \%$ responderam que sim, 33\% responderam que não e 33\% consideram regular, pois oferecem o necessário: "Risco a gente sempre tinha, empresa pequena, foi comprado maquinário antigo, foi comprando das empresas que foi se atualizando e vendendo pra ele. Tem coisas que nem, eu peguei o dedo, a empresa grande é tudo automatizado, ali não é tudo manual, tem muito risco. Fora isso, é adequado." (Sujeito 6). Consideram que a divisão de trabalho e o tempo para execução nem sempre corresponde as expectativas, de modo que gera uma sobrecarga de tensão para manter o ritmo acelerado e cumprir com a finalização da tarefa. Sujeito 6 "Tem que trabalhar mais rápido pra dar conta, a diferença ta aí, tem 700 peças por hora, se fosse mais devagar fazia 550. Eu me esforcei muito pra conseguir e dar o que eles pediam, se eu falasse que não... Ela não é justa. Você não pode perder tempo, você é que nem uma máquina mesmo, você tem que ter um espaço para respirar." 
Outros relatos: "Não, era muito sobrecarga em mim e os outros aliviados, tanto que no dia do acidente agente tava fazendo a medidas dos moldes dos estampos eu tava fazendo o outro falou que ia fazer me ajuda, um tava na produção que é no outro barracão, outro tava no banheiro, outro tava passeando pra outro lugar." (Sujeito 11)

Com relação às mudanças necessárias para melhorar o trabalho, 25\% das pessoas salientaram a importância da compreensão por parte dos líderes, 17\% mais pessoas no posto de trabalho e $17 \%$ remuneração, $8 \%$ diminuição das horas trabalhadas, $8 \%$ união, $8 \%$ nenhuma modificação, $17 \%$ não responderam:

"Ahh.. acho que eles deveriam tratar a gente melhor, sabe?! Porque lá onde eu trabalho dá impressão que a gente não significa nada, não quer saber se a gente ta cansada, se você tem família. Tem que trabalhar no sábado, no domingo, não pergunta se a gente pode, já fala que tem que vir. Se tratasse a gente com mais respeito, educação. Tem uma encarregada que xinga, que humilha mesmo, pegar no pé". (Sujeito 7) "Mais pessoas pra me ajudar, cê entendeu? Pouca pessoa pra muito serviço. Se tivesse mais uma pessoa pelo menos, me ajudaria muito. Outras coisas não vou nem comentar. A gente tem curso de capacitação a noite, aí chega lá não pode executar. Isso aí é difícil de explicar, agora só eu vou falar? Eu comecei a fazer o que mandaram lá, já ficaram blá blá, então nem vou perder meu tempo". (Sujeito 3) -

Quando os trabalhadores foram questionados sobre com era o seu ritmo de trabalho antes de se afastar do mesmo, 58\% dos entrevistados responderam que era "agitado": "Eles queriam que tirassem a produção pro dia, aí tinha que esforçar mais. É mais corrido, mais apertado. Não tinha tempo de parada, era diretão. Você tem que entregar tantas peças à tarde. Era 2, 3 mil peças e não tinha outra máquina para ajudar. Às vezes o encarregado ia lá pra ajudar. Daí depois eu vim pro CEREST, aí eles foram lá, mudaram as máquinas, aí eles melhoraram, mas é bem cansativo. Tem bastante gente com problema na mesma máquina que eu tava. Um outro pegou, largou lá, se afastou também, agora ele voltou". (Sujeito 2)

Esses relatos se convergem para os apontamentos de Souza et al (2010), Oliveira et al (2010) e Ulhôa et al (2010) no qual as interações compreendidas entre trabalhadores e as condições de trabalho podem afetar sua saúde. Além disso, as condições de trabalho que envolvem alta demanda, baixo controle e 
falta de apoio social podem ser prejudiciais à saúde física e mental dos trabalhadores.

\section{Relações sociais dos trabalhadores}

Quando os trabalhadores foram questionados se ficam sabendo de todas as mudanças e decisões que ocorrem na empresa, o que se pode observar foi que das 12 entrevistas realizadas, a maioria não ficava sabendo das mudanças e tomadas de decisões ocorridas na empresa, ou seja, 33\% disseram que não, $25 \%$ em alguns casos e $17 \%$ ficam sabendo por outras pessoas que não os líderes imediatos. Tendo como indício que as informações na maioria das vezes não eram comunicadas por seus respectivos responsáveis, podendo sofrer uma série de alterações e ruídos, conforme relato: "Ah, tipo assim, é coisa de última hora. Aí uma fala pra uma e vai espalhando. Ela deixa pra ultima hora, não fala muito as coisas pra gente". (Sujeito 7). Para Martins et al (2000) considera que a falta de valorização profissional gera sentimento de inutilidade, remetendo à falta de qualificação e de finalidade do trabalho.

Com base na questão que se referia a qualidade das relações com a equipe de trabalho, a $67 \%$ dos entrevistados parecem estar satisfeitos: "É como te disse, até o momento a gente ta se conhecendo, é um namoro ainda, quando eu falei da entrevista a diretora me deu a maior força, se você quer fazer, vai, então eu acho que isso é total, ela podia falar não estamos em época de matrícula não vou te dispensar pra ir até lá" (Sujeito 5)

De acordo com a questão referente ao relacionamento social na empresa a maioria das pessoas parecem satisfeitas tendo como grau de respostas para a questão, sendo que $18 \%$ apontaram com ótimo e $45 \%$ como bom: "Era muito bom, porque a gente trabalhava na área de mecânica, tinha livre acesso em todas as áreas, desde a parte de escritório, produção, tinha uma boa relação com todo mundo". (Sujeito 4)

Os trabalhadores relatam sentir dificuldade em receber feedbacks negativos sobre suas tarefas, principalmente pelo feedback ser inadequado quanto ao tipo de cobrança em que há falta de recurso. "A...fico magoado, quando isso é verdade entendeu? Muitas vezes você recebe e não é verdade" (Sujeito 8). "A eu não me sinto bem não, eu fico meio quieto, mas fazer o que?" (Sujeito 4). "A gente fica um pouco chateada se a gente entender que errei a gente tenta concertar a situação, melhorar da próxima vez" (Sujeito 7). Quando 
reconhecidos pelo trabalho sentem-se até aliviados fisicamente. "Todo mundo gosta de ser elogiada, é ótimo, eu as vezes sinto até que melhora a dor. É um estímulo, você passa por cima de muita dor". Sujeito 5. A percepção dos trabalhadores quanto a comunicação da empresa parece ser equilibrada, parte considera ruim, e parte considerada adequada. Porém, notou-se que sobre as mudanças e decisões que ocorrem na empresa, na maior parte dos casos, essas informações são omitidas. "Nenhuma (risos) a gente não sabe, um ou outro fica sabendo, mas pra mim não passa não." (Sujeito 2)

\section{Satisfação e motivação}

Com base na questão sobre motivação para trabalhar nessa empresa, 50\% dos entrevistados disseram que sim e 50\% que não: "É um serviço que eu gosto de fazer, eu adoro cozinhar. Não sei o que vai ser de mim se eu não puder mais cozinhar. Eu gosto das crianças, pra mim ta muito difícil, que deu essa depressão em mim de não conseguir mais fazer isso". (Sujeito 3) - "Hoje não me sinto motivado hoje eu me ponho no meu lugar, balanço o braço dói tudo, é diferente. Ali você trabalha como uma máquina eu me desgastei muito nessa empresa, se eu pudesse voltar um tempo atrás e não trabalhar nessa empresa, nem que fosse pra ganhar menos, era trabalhar em compasso, chega uma hora eu não aguento". (Sujeito 6)

Segundo o item relacionado ao grau de satisfação para o trabalho, $83 \%$ dos entrevistados responderam que sim: "Enquanto eu tava exercendo eu tava muito satisfeito, mesmo tendo as dificuldades que eu tinha eu me sentia muito útil, uma pessoa satisfeita, preenchida na minha profissão". (Sujeito 4)

De acordo com o questionamento relacionado ao momento que os trabalhadores perceberam que era necessário se afastarem, a maioria dos entrevistados relatou à causa ter sido por indicação médica (67\%): "Nesse caso de 1 ano, a ex diretora começou a brincar com a minha restrição, que aí eu procurei ajuda aqui no CEREST, me encaminhou na psicóloga e a gente conversou que eu coloquei pra fora que tava pegando ódio de trabalhar, quando eu travo é que o meu emocional já foi, o meu emocional manda muito em mim e minha psicóloga tem me ajudado muito a entender. Se o emocional não corre bem comigo, a minha coluna para. Eu acho que a minha muleta para dar um basta, foi o que aconteceu nesse afastamento, ela me humilhou numa festa do dias das mães, no meio de todas as mãe, eu tava lá como voluntária, mas era 
crianças se apresentando eu queria ver, ela me mandou pegar bancos e eu disse que não posso carregar peso, eu sei o tamanho da minha dor, aí ela falou que um banco não vai te aleijar, então ficou um clima". (Sujeito 4)

Para Dejours (1992) a somatização de indivíduos, pode ser entendida como um processo no qual o indivíduo estando em conflito mental acaba por desencadear no corpo, desordens endócrino-metabólica, sendo esta o ponto de partida para uma doença somática. Entretanto este caso pode ser ilustrativo neste sentido, pois o trabalhador estando carente de recursos internos, ou seja, ele não consegue lidar com o ambiente externo, com as pessoas, líderes, e equipe de trabalho, não conseguindo expor suas idéias e pensamentos, referentes às concepções que o ambiente social e as condições de trabalho que está inserido oferecem, pode com isso ter sua saúde afetada.

Em relação a conciliar o trabalho com a vida pessoal grande parte dos entrevistados disseram conseguir (75\%): "Eu não misturo, não levo serviço pra casa, o que acontece lá, nem comento com a mulher. Fica apertado, quando não dá também largo. Dá, tem que dar, depende do querer da gente né. O dia que você quer sair pra pagar as contas não dá, cê chega tarde em casa, às vezes chega 6 horas, num dá, na parte da noite já tem que preparar meu amanhã, senão... Dá, apertado, mas dá (risos)". Sujeito 2

Quando os trabalhadores foram questionados sobre quais as principais dificuldades que encontram para desempenhar suas tarefas diárias no trabalho, observou-se que $67 \%$ dos entrevistados apontam certas dificuldades como: dor, necessidade de clareza nas informações, aumento no quadro de colaboradores, melhora nos equipamentos e ferramentas entre outras, contra $33 \%$ que relataram não possuir dificuldades. Notou-se aqui alguns discursos que comunicam possíveis dificuldades: "O convívio com pessoas, que conviver com pessoas é pior do que se trabalhar com máquinas". (Sujeito 11). "Eu acho que falta de cooperativismo entre os funcionários" (Sujeito 8). "A clareza na hora de passar as informações, eu acho que esse é um grande empecilho na hora de estar desempenhando as funções". (Sujeito 1).

Conforme relatado por Rebouças et al (2007), a satisfação no trabalho pode ser entendida como um estado emocional resultante da interação de profissionais, suas características pessoais, valores e expectativas com o ambiente e a organização do trabalho. O impacto do trabalho nos profissionais envolve as repercussões dos fatores relacionados ao trabalho sobre a saúde e o 
sentimento de bem-estar da equipe. Neste caso os relatos dos trabalhadores mencionados apontam que a interação entre pessoas e o trabalho em equipe são fatores primordiais para o andamento do trabalho e a satisfação do trabalhador.

Um dos aspectos mencionados por Souza et al, (2010) como fator contribuinte para o adoecimento no trabalho é a questão psicossocial e dentro deste o distanciamento entre grupos de mandos e de subordinados; isolamento social no ambiente de trabalho; conflitos de papéis, conflitos interpessoais e falta de apoio social.

Pode-se também atrelar a esta questão o sentimento dos trabalhadores quando questionados em relação ao relacionamento social na empresa, onde $33 \%$ consideram regular, $17 \%$ ruim, contra $50 \%$ que o consideram bom, o que engloba a questão apontada por Souza et al, (2010) mencionada no parágrafo anterior. Alguns discursos que apontam para essa dificuldade: "É muito pouco, a gente na empresa... a gente é... eu vejo que tem um pouco de divisão de departamentos ai então a... esse relacionamento eu acho que é um pouco deficiente". (Sujeito1). "A quase não existe a relação com outro departamento aqui, não existe assim contato com outro departamento, com outro setor entendeu?" (Sujeito 8). "Mais ou menos ou quase pouco" (Sujeito 12).

Em relação à questão que envolvia a necessidade de mudanças para que com estas resultasse a melhoria no andamento do trabalho, $50 \%$ dos entrevistados propuseram melhorias, contra $50 \%$ que estão satisfeitos com o andamento atual do trabalho. Entre as melhorias apontadas estão: a união 17\%, e a clareza na informação $17 \%$, outros $8 \%$ apontaram maior compreensão por parte dos líderes e outros $8 \%$ melhoria nas ferramentas de trabalho." $A$ distribuição do trabalho seria uma diminuição na carga de trabalho para cada funcionário, se cada um fizesse a sua parte". (Sujeito 3). "É ...mais colaboração entre todos e seguir as regras e desempenhar as funções". (Sujeito 7). "Eu acho que deve ser, sei lá! Deve ser colocado assim, mais pessoas pra ta olhando quem realmente ta trabalhando e quem não tá, porque às vezes existem pessoas no ambiente de trabalho que não poderia ta ali, entendeu?" (Sujeito 8). "Informação, comunicação" (Sujeito 6).

É possível perceber que independente da situação que o trabalhador se encontre, cada indivíduo possui uma necessidade diferente, cada indivíduo é único na sua singularidade e uma organização nem sempre está preparada para essas diferenças. Delinear o contorno do mundo moderno e, nele, do mundo do 
trabalho na atualidade significa atentar para o permanente processo de mudança instalado no dia-a-dia das pessoas, e em particular, dos profissionais, e elas se tornam cada vez mais rápidas, em todos os segmentos da vida. (Almeida, 2004)

\section{CONSIDERAÇÕES FINAIS}

Os objetivos do presente trabalho foram alcançados. Identificou-se, por meio dos relatos, as percepções dos indivíduos quanto ao ambiente físico e social relacionados ao trabalho. Um nota interessante é que muitos dos trabalhadores relataram gostar das atividades desempenhadas antes de se afastarem, demonstrando certo receio em não poderem mais exercer suas tarefas no trabalho. O que pode sugerir uma não desqualificação do trabalho.

Os relatos descritos parecem confirmar o que a literatura já apontou como fatores desencadeantes do desequilíbrio da saúde quanto aos aspectos biopsicossociais. Dejours (1992) relata que os indivíduos inseridos nas organizações de trabalho possuem uma história individual, são portadores de projetos, de esperanças e de desejos, mas que nem sempre estão alinhados com o cotidiano nas organizações. O alinhamento destes projetos, esperanças e desejos, mesmo que a priori não seja algo tangível devem ser levados em consideração, podendo começar com o "dar ouvidos", ou amparo àquele que necessita expor suas idéias e opiniões, o que nem sempre ocorre. O sofrimento do trabalhador deve ser levado em consideração em antemão ao seu adoecimento propriamente dito.

Sugere-se ainda que tenham gestores mais preparados e atentos aos seus colaboradores, uma vez que o sofrimento não surge inesperadamente, mas sim por uma série de fatores que muitas vezes passam despercebidos, como um feedback positivo, funções adequadas para cada limitação, além de fazer-se necessário um psicólogo como parte da equipe de uma organização, observando a singularidade, intervindo preventivamente e remediando nas atuações da saúde do trabalhador, evitando o sofrimento por estresses desnecessários.

Vale ressaltar algumas limitações deste trabalho: notou-se que os participantes, embora tenham consentido com a gravação dos relatos, demonstraram certo incômodo com o gravador. É aconselhado também que se amplie a área de estudos no que diz respeito à saúde do trabalhador, principalmente ampliando o número de participantes da pesquisa, a fim de melhor conhecer e mapear essa demanda. Para finalizar, as palavras de Navarro 
(2003) são pertinentes, quando afirma que embora haja uma complexidade no mundo do trabalho e as mudanças rápidas que ocorrem por conta disto, o homem ainda precisa ser tratada como o ser humano que é.

\section{REFERÊNCIAS}

Almeida, L. (2004). O trabalhador no mundo contemporáneo: Psicodrama nas organizações. São Paulo: Agora.

Borsoi, I. C. F. (2007). Da relação entre trabalho e saúde/relação entre trabalho e saúde mental. Psicologia e Sociedade, 19(n. especial), 103-111.

Dejours, C. (1992). A loucura do trabalho: Estudo de psicopatologia do trabalho (5. ed. Ampliada). São Paulo: Oboré.

Fontes, A. P., Neri, A. L., \& Yassuda, M. S. (2010). Enfrentamento de estresse no trabalho: relações entre idade, experiência, autoeficácia e agência. Psicologia Ciência e Profissão, 30(3), 620-633.

Luz, R. (2007). Gestão do clima organizacional (30 ed.). Rio de Janeiro: Qualitymark.

Manetti, M. L., \& Marziale P. H. M. (2007). Fatores associados à depressão relacionada ao trabalho de enfermagem. Estudos de Psicologia, 12(1), 7985.

Martins, L. M. M., Bronzatti, J. A.G., Vieira, C. S. C. A., Parra, S. H. B., \& Silva, Y. B. (2000). Agentes estressores no trabalho e sugestões para amenizálos: opiniões de enfermeiros de pós-graduação. Revista Escola de Enfermagem da USP, 34(1), 52-58.

Nascimento, E. C., Nascimento, E. \& Silva, J. P. (2007). Uso de álcool e anfetaminas entre caminhoneiros de estrada. Revista de Saúde Pública, 41(2), 290- 293.

Navarro, V. L. (2003). O trabalho e a saúde do trabalhador na indústria de calçados. São Paulo na Perspectiva, 17(2), 32-41.

Oliveira, J. R. S., Viganó, M. G., Lunardelli, M. C. F., Canêo, L. C., \& Goulart Jr. E. (2010). Fadiga no trabalho: Como o psicólogo pode atuar? Psicologia em Estudo, 15(3), 633-638.

Rebouças, D., Legay, L. F., \& Abelha, L. (2007). Satisfação com o trabalho e impacto causado nos profissionais de serviço de saúde mental. Revista de Saúde Pública, 41(2), 244-250. 
Santos, A. F. O., \& Cardoso, C. L. (2010). Profissionais de saúde mental: manifestação de stress e burnout. Estudos de Psicologia de Campinas, 27(1), 67-74.

Sato, L., \& Bernardo, M. H. (2005). Saúde mental e trabalho: os problemas que persistem. Ciência e Saúde Coletiva, 10(4), 869-878.

Silva, A T. C., \& Menezes, P. R. (2008) Esgotamento profissional e transtornos mentais comuns em agentes comunitários de saúde. Revista de Saúde Pública, 42(5), 921-929.

Souza, S. F., Carvalho, F. M.; Araújo, T. M., \& Portode, L. A. (2010). Fatores psicossociais do trabalho e transtornos mentais comuns em eletricitários. Revista de Saúde Pública, 44(4), 710-717.

Ulhôa, M. A, Marqueze, E. C., Lemos, C. C., Silva, L. G., Silva, A A, Nehme, P., Fischer, F. M. et al. (2010). Distúrbios psíquicos menores e condições de trabalho em motoristas de caminhão. Revista de Saúde Pública, 44(6), $1130-1136$.

Contato: taismmanso@gmail.com, pires_alinec@yahoo.com.br, fernando.ugo@hotmail.com.br,marildapsi@uol.com.br

Recebido em: 10/10/2011

Revisado em: 18/11/2011

Aceito em: 05/12/2011 